\title{
"La historia del arte y la estética está por hacerse": presencia del folclore y Fidel Sepúlveda en revista Aisthesis
}

\author{
Felipe Espinoza Villarroel \\ Instituto de Estética, Facultad de Filosofía, Pontificia Universidad Católica de Chile. \\ fpespino@uc.cl
}

En los cincuenta años de trayectoria de la revista Aisthesis, si nos preguntamos por la presencia del folclore en ella en tanto reflexión estética, inevitablemente la figura del profesor Fidel Sepúlveda Llanos (1936-2006) aparece como un destacado e irrenunciable hito. Tal vez el mayor mérito de Fidel haya sido, precisamente, descubrir el enorme potencial reflexivo que el folclore tenía, estudiándolo puntualmente desde un ámbito hasta ese momento inexplorado e insospechado: su dimensión estética. Hasta ese momento, si colocamos los inicios de la década de 1980 como la época donde el folclore comienza a ser tratado sistemáticamente desde una perspectiva estética, la disciplina fue abordada desde una mirada etnográfica y principalmente centrada en lo musical, mas no se lo consideraba como un ámbito de la cultura del cual pudiera reflexionarse desde un sustrato filosófico y, menos aún, estético. Nuestro recordado Fidel, no abandonando nunca la raigambre telúrica conectada con su Cobquecura natal, colocó a la disciplina folclórica en la primera línea de los estudios estéticos, descubriendo y releyendo su enorme riqueza antropológica, simbólica y existencial, y abriendo de paso un camino fecundo para futuros investigadores, al replantear las miradas académicas sobre lo que se conoce como "lo folclórico" o "lo popular".

Antes de pasar a revisar los principales hitos de lo folclórico y su posicionamiento como materia estética a partir de las publicaciones de la revista Aisthesis, resulta preciso nombrar a los precursores del estudio de la disciplina en nuestro país. En ese plano, nos encontramos con nombres como los de Ramón Laval, Rodolfo Lenz y Julio Vicuña Cifuentes, los cuales, unos más, otros menos, mantuvieron la impronta "cientificista" en el estudio del folclore, siguiendo la aproximación que surge a mediados del siglo XIX en Inglaterra. Incluso algunos de estos investigadores, como es el caso de Lenz, 
provenían de suelo extranjero y de escuelas europeas, y el esfuerzo por realizar una "ciencia del folclore" queda claramente plasmado en sus trabajos.

Herederos de estas primeras aproximaciones y documentos son sin duda los trabajos de dos figuras también señeras en el ámbito de las investigaciones en torno al folclore en Chile: Oreste Plath y Manuel Dannemann. El primero, de formación literaria, fue un magnífico cronista e indagador de un complejo y rico acervo en torno a lo folclórico, legándonos una extensa bibliografía y explorando áreas que hasta el momento no eran materia de estudio (como el folclore urbano, por ejemplo). En tanto, Manuel Dannemann, un heredero más directo del grupo de investigadores precursores ya señalados, trabaja a partir de su formación como antropólogo y cientista social, desde la cual trata de establecer métodos rigurosos y claros en torno a la investigación folclórica, realizando además recopilaciones y sistematizaciones con unna intención omniabarcadora (Enciclopedia del folclore en Chile, Atlas del folclore). De estas dos líneas, el trabajo del Instituto de Estética en torno a lo folclórico en estos cincuenta años, y puntualmente lo realizado por Fidel Sepúlveda, aparece como un nuevo y fructífero ámbito.

Cabe señalar que los primeros artículos del profesor Sepúlveda en Aisthesis (números 3, 5 y 10, década de 1960) no están en la línea de la investigación folclórica, sino más bien responden a su formación literaria y a la preocupación por instalar la reflexión estética como un ámbito autónomo de conocimiento. Sin embargo, en los números 8 y 9, veremos los primeros asomos de lo folclórico en la revista con dos artículos: uno, del citado profesor Dannemann en torno a la música folclórica chilena (Aisthesis 8, 1974), y un segundo trabajo de otro destacado profesor del Instituto, quien fue parte tanto de su fundación, como artífice del folclore en cuanto disciplina de estudio académico: Carlos González Vargas. En el número 9 de Aisthesis, se encuentran sus primeros trabajos en torno a lo que sería uno de sus ámbitos más pertinazmente estudiados: la cerámica chilena.

Los venideros años ochenta marcarán, sin duda, un punto de inflexión en torno a la presencia de lo folclórico en la revista: luego de su estadía doctoral en España, Fidel Sepúlveda comienza a escribir enfocando prácticamente la totalidad de su interés reflexivo al fenómeno folclórico y, específicamente, a lo que él llamará "cultura tradicional".

Un primer indicio de lo señalado es el artículo "Materiales para una estética del entorno" (Aisthesis 14, 1982), donde si bien no hay una mención explícita hacia lo folclórico y lo tradicional, se delinean y preparan los materiales que justamente estarán en la base de su reflexión estético-antropológica posterior. El mencionado es un trabajo visionario donde Fidel vislumbra la posibilidad de una "ecología estética", vinculando a la estética con la relación hombre-medioambiente. Creemos que la experiencia más originaria y originante de los primeros años de vida de Fidel en los campos de su natal provincia de Nuble decantan y toman cuerpo reflexivo y proyección universal en estas líneas. 
Desde el siguiente número, el foco investigativo estará directamente relacionado con la disciplina; ahí aparecerá el conocido texto "Notas para una Estética del Folklore" (Aisthesis 15, 1983), en el que Fidel sentará las bases de su concepción en torno a la cultura tradicional y el folclore, junto con la posibilidad de postular una estética foclórica, en un gesto totalmente innovador y que constituye un cualitativo aporte al desarrollo de la disciplina hasta el momento. La cita que da título a estas líneas proviene de dicho trabajo y fue escogida por su radicalidad y claridad respecto a la postura de Fidel en cuanto a refundar una estética desde un lugar "otro".

Cabe señalar que el mencionado número lleva por título "Estética y Folklore", conformado además por los siguientes artículos: "Algunas reflexiones sobre la artesanía y el arte", de Raimundo Kupareo; "La cultura de la simetría. EL viejo Thoms y el nuevo folklore", de Manuel Dannemann; "Conceptualización del folklore en Hispanoamérica y en la Argentina”, de Marta Blanche; "El folklore en Isla de Pascua”, de Camila Laureani; y una particular entrevista de Fidel a Margot Loyola como cierre del número.

En las siguientes entregas, lo folclórico aparecerá como un tema instalado en la revista, convirtiéndose así en un contenido recurrente del dossier de Aisthesis en su medio siglo de vida. En el número 16 de la revista, aparecen los siguientes artículos relacionados con el tema: "Valor estético del folklore chileno: El canto por angelito", de Fidel Sepúlveda; "Un método de análisis estructural del romancero", de Manuel Gutiérrez; "La cueca, danza nacional de Chile”, de Juan E. Pérez; y "Narraciones míticas de Chiloé", de Jaime Blume. Relevante es además una mesa redonda en torno al folclore transcrita íntegramente en Aisthesis 18, en la cual participan figuras relevantes de la cultura chilena como el propio Fidel Sepúlveda, Isabel Aninat, Raquel Barros, Jorge Cáceres, Carlos González, Nicanor Parra, Gastón Soublette y Juan Uribe. A este material, valioso en cuanto a su potencial y a su gran actualidad respecto del estado de la disciplina, se agrega un texto de Fidel que marcará una de sus principales preocupaciones venideras, referida no solamente a lo investigativo sino también a la gestión y el quehacer respecto de lo folclórico: "Folklore y cultura regional: una aproximación estética".

La segunda mitad de la década continuará con el tema presente a nivel de publicaciones, a lo que se agrega la realización del Programa de Arte y Cultura Tradicional (1986-2004), del cual Fidel fuera fundador y director. A nivel de publicaciones se encuentra Aisthesis 20 (1987), número dedicado íntegramente al cuento folclórico, otro de los grandes temas en que Fidel se embarcó como investigador, donde destaca su original y contundente artículo, "El cuento folklórico: una vía al ser", acompañado de un par de textos enfocados en nuestra realidad folclórico-popular: "Acercamiento antropológico a la religiosidad popular", de Jaime Moreno, y "El tiempo y el espacio en la narrativa folklórica chilena", de Jaime Blume. Cierra la década Aisthesis 22 o "Estética y Folklore IV", donde Fidel, en su artículo "Tres calas estéticas en el romancero hispano-chileno", aborda la temática del romancero tradicional, conectándola con otra de sus más persistentes preocupaciones en torno a lo tradicional: su dimensión 
poética. A este último texto lo acompañan un par de sugerentes escritos: “¿Artesanías tradicionales, artes populares? En busca de una terminología clarificadora”, de Carlos González y "El cancionero chilote", de Gastón Soublette, tercer profesor que desde los primeros años de vida del Instituto, y hasta hoy, se ha encargado de mantener en primer plano de reflexión y estudio el tema de la cultura tradicional, en tanto ámbito de pensamiento estético y espiritual.

El tercer y último período agrupa artículos en torno al folclore de las décadas de 1990 y 2000. Si bien hay una disminución en cuanto a cantidad de textos dedicados al tema, se publicarán trabajos significativos, que recogerán parte importante de lo investigado y reflexionado en la década anterior: por ejemplo, "Ética y estética del cuento tradicional", de Fidel Sepúlveda (Aisthesis 27, 1994), al que se agrega "Notas sobre el concepto de cultura popular", de Miguel Alvarado Borgoño. A lo largo de la década, se sumarán "Estética: educación de los sentidos y sentido de la educación" (Aisthesis 29, 1996), donde Fidel toma el modelo de la cultura tradicional como paradigma educativo; y el significativo discurso de incorporación a la Academia Chilena de la Lengua, titulado "Estética de la cultura popular chilena" (Aisthesis 31, 1998), una lúcida síntesis del trabajo que han significado los veinte años dedicados a pensar lo folclórico desde la estética.

La década del 2000 significa la última etapa de publicación del profesor Sepúlveda, antes de su fallecimiento en 2006. En este lapso, no obstante, el tema de lo tradicional seguirá en boga, diversificado hacia otras manifestaciones que son resultado de una paciente y atenta lectura del universo de la cosmovisión popular. Aparecen artículos como "La identidad en la Lira Popular" (Aisthesis 34, 2001); "Artesanía como patrimonio cultural: desarrollo, fomento y protección" (Aisthesis 36, 2003), texto significativo por sus proyecciones y por relevar un tema que, como vimos, estuvo desde los inicios del Instituto; y su último artículo publicado, el cual atiende a una de las dimensiones de lo popular que más motivó y preocupó a Fidel, en tanto expresión genuina de identidad: "Fiesta y vida" (Aisthesis 38, 2005). Cabe agregar que en estos años aparecen otros artículos relacionados con el tema y que de alguna forma tienen cabida gracias a la labor que Fidel y otros investigadores realizaron para posicionar a la cultura tradicional y al folclore como áreas de estudio y reflexión en el mismo nivel de las otras materias académicamente legitimadas: por ejemplo, "El universo del guitarrón chileno", del poeta popular Francisco Astorga (Aisthesis 33, 2000); "La Lógica de la Oralidad", de otro querido profesor como fue Andrés Gallardo; y el no menos significativo "Homo Aestheticus", de Genaro Arias (Aisthesis 34, 2001), primer trabajo que intenta sistematizar lo que podríamos denominar como "la estética de Fidel Sepúlveda”.

Algunas palabras finales para las proyecciones que tiene la disciplina y, en particular, su porvenir al alero del Instituto de Estética y Aisthesis. Sin duda que el esmerado y acucioso trabajo antes reseñado es el gran antecedente para quienes nos dedicamos actualmente al estudio, enseñanza e investigación de los distintos ámbitos 
relacionados con la cultura tradicional. Hay, entonces, el deber de continuar con un legado inaugurado y dejado en un muy alto nivel por los maestros que nos precedieron. En segundo término, está el interés de continuar esta línea de investigación por el porvenir de la misma disciplina folclórica para el futuro de Chile y el deber de volver a preguntarnos por nuestra esquiva identidad. Esta última fue una de las principales motivaciones, quizás la única y más importante, que acicateó a Fidel Sepúlveda a dedicar una vida completa al estudio del folclore, lo popular y lo tradicional. Actualmente, el Instituto imparte cursos tanto en su malla mínima como de formación general en que estos temas aparecen de una u otra forma ("Experiencia estética y Cultura Tradicional", "Folclore Chileno"), además de organizar periódicamente actividades de extensión y publicaciones relacionadas con la temática (talleres de escritura de décimas y sabiduría tradicional, coloquios y publicaciones en torno a la cueca, la tonada, las animitas, entre otros). Destaca la presencia del tema en el último Simposio de Estética de este presente año 2016, donde ámbitos como el de la lira popular y la guitarra chilena fueron relevados. Por último, vayan estas modestas líneas en recuerdo del querido profesor Fidel Sepúlveda, maestro de generaciones y uno de los pioneros en lo que refiere a las investigaciones folclóricas y a su aún no del todo explorada dimensión estética. 